\title{
ICT INTEGRITY: BRINGING THE ACS CODE OF ETHICS UP TO DATE
}

\author{
Michael Bowern, Oliver K. Burmeister \\ Committee member of the Australian Computer Society's Committee on Computer Ethics \\ Charles Sturt University \\ Wagga Wagga, NSW, AUSTRALIA \\ Email: mike.bowern@anu.edu.au \\ Don Gotterbarn \\ Director Software Engineering Ethics Research Institute \\ Chair ACM Committee on Professional Ethics \\ Professor of Computer Science, \\ East Tennessee State University, USA \\ John Weckert \\ School of Information Studies, \\ Center for Applied Philosophy and Public Ethics \\ Charles Sturt University \\ Wagga Wagga, NSW, AUSTRALIA
}

\begin{abstract}
Over the last 20 years the ICT industry has seen many developments and changes, such as faster and smaller computers, many new digital devices, the convergence of this digital technology, the internet, and operational aspects such as outsourcing. Governments and professional societies have discussed the issues related to these changes in the media, yet the Australian Computer Society's Code of Ethics has not changed. This paper discusses the need to change the ACS Code, the issues to be addressed, and procedures to be followed, if changes are to be made. These issues include, amongst others, the lack of specificity of the Code, and the absence of a way to decide between ethical principles which may conflict in some situations, and how to resolve such conflicts. With the focus on the Australian context, the ACS Code's relationship with international standards and codification of ethics are considered, and the paper discusses what lessons can be learned from overseas experience in modifying codes. The paper concludes by outlining the next steps to bring the ACS Code up to date.

Keywords: Codes of ethics, codes of conduct, codes of practice, ACS, IFIP, ICT ethics, professional societies.
\end{abstract}

\section{INTRODUCTION}

Recognition of professionalism in information and communications technology (ICT) in Australia requires that members of the Australian Computer Society (ACS) adhere to a Code of Ethics (ACP, 2005). Systems using ICT are not produced in an ethical vacuum. The values of many stakeholders are involved. Typically these stakeholders are suppliers, vendors, employees, contractors, trade 
unions, clients, and those who are affected by the delivery of the final product. Increasingly, especially in globalisation and offshore issues, professional societies and politicians can also be involved. One way that professional societies address the diversity of values of so many different stakeholders is by requiring their members to adhere to their code of ethics. Major functions of professional codes of ethics include the requirement to articulate ethical standards of the profession; to educate practitioners and the public about ethical obligations; and to provide guidance to resolve ethical quandaries (Anderson et. al., 1993). Philosophical dialogue about alleged difficulty with codes of ethics includes works by Luegenbiehl (1983), Ladd (1995), Fairweather (2001) and Tavani (2004).

There are numerous terms in the literature for professional codes of 'ethics'. In this paper we follow the guidance of the International Federation for Information Processing (IFIP) (Berleur, et. al, 2004), in discussing two types of codes.

The first type, which Berleur et al refer to as the code of 'ethics/conduct', has a set of high level statements concerning such issues as honesty and integrity. This code governs 'how the person to whom it applies conducts him [sic] or herself in an ethical manner' (Berleur, 2004, p 11). To avoid confusion, this type will be referred to as the code of conduct in the rest of this paper.

The second type of code refers to a 'code of practice' for professionals, which 'governs how the person to whom it applies carries out his or her work technically' (Berleur, 2004, p 11). This code includes a set of detailed statements related to the professional's particular occupational environment. These statements of practice are more specific and more likely to change over time, than are the conduct statements. For example, the desire for honesty is less likely to change over time, than is the interpretation of the way in which honest dealings in the occupational environment are to function.

Typically, a professional society would define both types of code for its members in a single document, a good example being the Software Engineering Code of Ethics and Professional Practice. This is 'the standard for teaching and practicing software engineering by the ACM and IEEE-CS' (SECEPP, 1999). In this paper, reference to a 'code' or a 'code of ethics' means a document which includes both types of code, covering conduct and practice. Other references will be made to a specific type of code under consideration, for example a 'code of practice'.

The problem we address in this paper is one in applied philosophy. Presuming that a professional code of ethics can usefully serve the education and guidance functions, there are three critical questions.

1. How can one identify if the changing technology has reduced the ability of a code of ethics to be useful in ethical assessment? The code is to act as a guide. It should not be subject to frequent change, as each new technology or ICT work process comes along. Yet the inevitability of change in the ICT industry leads one to recognise that certain changes may require a review of a code of ethics, particularly with respect to its code of practice.

2. Given a code that no longer addresses some of the significant issues, what can be done to consistently revive the ability of the code of practice to serve this function without undermining the existing strengths of the code of conduct?

3. For codes which do not specifically distinguish the practice and the conduct elements, how can one modify the practice elements without also modifying the conduct standards?

These concerns are not new. Each professional society has had to grapple with them at one stage or another. IFIP has recently suggested a series of high level guidelines to assess the strengths and 
weaknesses of codes of ethics (Berleur, 2004). Perhaps these guidelines could also help with the first of the above points, namely to re-evaluate the efficacy of an existing code, once significant change has occurred in the ICT industry?

Rapidly changing technology can have a negative impact on the adequacy of its professional codes; this paper describes that impact, and ways to ameliorate it.

In the ICT industry one has always had to deal with the relationship between ethical assessment and technology. A brief examination of the evolution of ICT professionals' codes will show that at earlier stages modifications were made to the codes to meet technological changes; and a desire to include their expanded sense of professional responsibility and behaviour occasioned by some of these advances. For example, a major revision of the ACS code occurred in 1985, to address the concerns over the rise of computer based crime (Coldwell, 1987).

Many changes to the ICT industry have taken place since the last major revision of the ACS code, 20 years ago. This paper discusses some of the factors which could be considered when reviewing the need to change the ACS code. The paper also briefly examines reasons for the modifications to the ACM/IEEE ethical standards.

The paper then focuses on changes currently planned and in progress by the ACS. The paper identifies what were perceived as the major ethical shortcomings, and indicates the common elements required to meet the impact of changes in industry practice, in the education and technical functions of the ACS code. These common elements may be used as guidelines in the next generation of ethical code reform. The paper ends by looking at how the ACS plans to progress the redrafting of its Code of Ethics and its associated documents.

\section{WHEN DO CHANGES IN ICT NECESSITATE CHANGES TO THE CODE OF ETHICS?}

In a domain which changes as frequently as that of ICT, a change in work practice, or the advent of some new technology, should not of itself constitute grounds for changing a code of ethics. Examples of the types of change that could make us consider revising or reviewing our codes include the rise of the Internet, the increased use of outsourcing and off-shoring, and the arrival and impact of micro/nano computing. However, codes cannot be reviewed with every change that occurs.

To avoid ineffective continuous code reviews, procedural guidelines are needed within a professional society, that ensure regular review of its code or codes. How frequently should such a review be undertaken? Given the logistical difficulties involved, and based on observations of previous changes to codes in Australia and the USA, the authors contend that codes ought to be reviewed at least every 10 years. The ACM code was reviewed and significantly revised in 1992 and reviewed again in 1998, but not since. The ACS code was reviewed in 1975, and again in 1985, but not since then. By this reckoning a review of the ACS code is long overdue. The review procedure ought to also allow for reviews that are determined by major technology changes. The advent of a biological computer implanted in the brain might be the sort of thing that justifies immediate code review rather than waiting a prescribed period of time.

Changes to codes of ethics have been motivated by a desire to include their expanded sense of professional responsibility and behaviour occasioned by some technological advances (Gotterbarn, 1996). Other changes have been made to include an aspirational component in the code. 
Why aspirational? To appeal for right behaviour when enforcement is not possible. In medicine and law, a breach of the code of ethics can mean loss of ability to practice one's profession. Not so in ICT. An ACS member can be held accountable, through the ACS Disciplinary procedures. But 80\% of ICT practitioners in Australia are not ACS members. Also, a member facing the ACS Disciplinary procedures could simply resign. Then s/he can continue to behave unethically; they simply can no longer claim to be an ICT "professional", which is a right that the Australian Council of Professions (ACP, 2005) has restricted to use by ACS members only.

Gotterbarn (2000), writing about experiences in the development of two codes of ethics in the USA, found that a critical issue is that of specificity, that is how prescriptive and detailed the code should be. Specificity has partly been addressed in the ACS Code of Ethics by recent work (Bowern, 2003) which resulted in a set of case studies identifying issues related to each of the clauses in the code. Some of the cases were drawn from published material (Burmeister, 2000; and Burmeister and Weckert, 2003); others were based on actual incidents known to the contributors, and a few were invented to complete the set. This exercise has revealed some shortcomings in the ACS Code. For example, the clause stating 'I must distance myself professionally from someone whose membership of the Society has been terminated because of unethical behaviour or unsatisfactory conduct' is unfair and unworkable (Bowern and Weckert, 2005).

Another approach to specificity is in the clauses of the code itself. In some instances the code of conduct does not change, but changes in ICT practice mean that the application of the code, as seen in the code of practice, is different. This task is simpler in codes where the code of conduct is distinguished from the code of practice, but it is much harder where there is no clear distinction in the document between ethics clauses and practice clauses.

\section{LESSONS FROM THE EVOLUTION OF THE ACM/IEEE CODE}

The solution to code modification is not purely technical. In the ACM/IEEE Software Engineering Code (SECEPP, 1999) it was important to include a broader sense of ethical reasoning in it. In evaluations of that Code by philosophers such as Herman Tavani, the decision making guidance of the preamble was considered one of its strengths. The international task force that developed the Software Engineering Code of Ethics and Professional Practice (SECEPP) was aware of a number of previously identified weaknesses of professional codes and made a conscious effort to address those in their code. Major motivations for writing the SECEPP were to document the professional responsibilities of software engineers, and those aspiring to be software engineers, in a way which could be used to educate practitioners and the public; and to facilitate ethical decision making in accordance with these responsibilities.

There have been two major problems in attaining these broad goals. One is based on the overly specific content of a code, in which the code attempts to define precisely a complete list of all of the ethical behaviour of a professional. Precisely defined codes are almost out of date the minute they are approved. This is especially true in professions related to industries as dynamic as those covering ICT. On the other hand codes which are too general, which treat ethical judgement at its most abstract level, have been criticised for their failure to provide adequate guidance. This attack is often generalized into a simplistic criticism of all codes, because codes can never be complete and anticipate every possible ethical situation (Fairweather, 2001). Such criticisms of codes are easily made, but are not very useful for they do not distinguish an incompleteness which is a shortcoming, from an incompleteness which is a strength. The SECEPP attempts to steer a middle ground between 
code imperatives which are too vague to give useful guidance, and the numbing precision of detailed imperatives which are locked to a particular stage of technology. Instead of appealing to a particular technical standard such as structured programming, which will change, the code appeals to the changing standards of the profession to address specific technical issues. By appealing to current best practices rather than naming a specific practice, as the standards change the particular technical items referred to in the code also change. This is a way to build a code which keeps current with the particular best standards of the profession.

The SECEPP code differs from that of the ACS, in that it also includes some general principles on ethical decision making to help guide the utilization of the specific clauses. For example, the preamble uses everyday English to advocate basic ethical approaches to decision making, and asks software engineers when making a decision guided by the specific principles in the code, also to:

- consider broadly who is affected by their work (utilitarianism);

- examine if they or their colleagues are treating other human beings with due respect (Kantianism);

- consider how the public, if reasonably well informed, would view their decisions (Gert and others); and

- $\quad$ analyse how the least empowered will be affected by their decisions (John Rawls).

The international SECEPP taskforce stated that 'without the aspirations, the details can become legalistic and tedious; without the details the aspirations can become high sounding but empty; together the aspirations and details form a cohesive code.' (Gotterbarn, 1999, p103)

Another concern is that in many cases it appears as if principles in a code could point in conflicting directions and thus the code itself does not direct the final decision. SECEPP admits it is incomplete, but does not suffer from issues of vagueness, because it provides general guidance for ethical decision making as indicated above. This still leaves open the possibility that the general principles may be in tension, in particular circumstances.

SECEPP has a clear hierarchy of values that facilitates the reduction of the instances of ethical tension. First, its eight principles are listed in an hierarchical order. If this does not help in the final decision making, then the code has an overriding principle - that a concern for health, safety and welfare has an overriding primacy. SECEPP consists of a set of principles (code of conduct statements) and details or examples for each of the principles (code of practice statements). Its preamble contains some guidance on understanding and using the code. It is the preamble which facilitates it addressing some of the older philosophical criticisms of professional codes.

This structure of the IEEE-CS/ACM code has raised other comments, whereby some philosophers have taken the SECEPP taskforce to task for including guidance about using the code as part of a document called a Code of Ethics and Professional Practice. As the following paragraph shows, this criticism has not deterred the adoption of the SECEPP by a significant number of software engineers.

The SECEPP taskforce identified a set of common elements to the profession of software engineering. They did this without identifying a particular professional society's preference for a particular culture's ethical style. The evidence for that is in the number of professional societies throughout the world that have adopted the Code and translated it into their native languages. Currently the Code has been adopted by professional societies in Argentina, Australia, Canada, China, Croatia, England, Italy, Israel, Japan, Mexico, Spain, and the United States. 


\section{CURRENT CODES OF THE ACS}

The ACS Code of Ethics (ACS Codes, 2005) comprises two sections. The first section is a simple policy statement plus a declaration of six Values and Ideals; which are then expanded in the second section, a detailed set of 37 statements, which are called the Standards of Conduct. This Code of Ethics is defined as part of the ACS National Regulations, to emphasise the importance of the code, and to ensure its prominence in the ACS body of documentation.

Supplementary to the Code of Ethics is the Code of Professional Conduct and Professional Practice (ACS Codes, 2005). This code was developed to provide more practical guidance in the day to day activities of ICT professionals. It is not part of the National Regulations, which means that it is easier to amend and update. Changes to the National Regulations require a vote by the National Council, followed by a vote by all members of the ACS. This has implications for future amendments to the codes. Figure 1 illustrates the codes.

\begin{tabular}{|c|c|}
\hline \multicolumn{2}{|c|}{ National Regulations } \\
\hline Clause \\
\hline 4. & $\begin{array}{c}\text { ACS Code of } \\
\text { Ethics }\end{array}$ \\
\hline 4.1 and 4.2 & Policy Statement \\
\hline 4.3 & Values and Ideals \\
\hline 4.4 to 4.10 & $\begin{array}{c}\text { Standards of } \\
\text { Conduct }\end{array}$ \\
\hline \multicolumn{2}{|c|}{ There is no identified Code of } \\
Professional Practice in the National \\
Regulations
\end{tabular}

\begin{tabular}{|c|c|}
\hline $\begin{array}{c}\text { Code of Professional Conduct } \\
\text { and Professional Practice }\end{array}$ \\
\hline \multicolumn{2}{|c|}{ Introduction } \\
\hline Section A & $\begin{array}{c}\text { Code of } \\
\text { Professional } \\
\text { Conduct }\end{array}$ \\
\hline $\begin{array}{c}\text { Sections B } \\
\text { to L }\end{array}$ & $\begin{array}{c}\text { Code of } \\
\text { Professional } \\
\text { Practice }\end{array}$ \\
\hline
\end{tabular}

Figure 1: The "Conduct" Overlap.

The Code of Professional Conduct is 'intended as a guideline for acceptable personal conduct for each IT professional practicing in the industry', and as such is complementary to the Values and Ideals and to the Standards of Conduct. There is some overlap between the standards of conduct and the codes of conduct.

The Code of Professional Practice is 'intended as a guideline for acceptable methods of practice within the IT industry'. The guideline is generic and addresses a range of aspects of the product life cycle, and acquisition, development, implementation and support processes. The Code of Professional Conduct and Professional Practice has not been updated since its adoption by the Society.

The ACS Code of Ethics (comprising a policy statement, the six Values and Ideals, and the Standards of Conduct) is a general code applicable to virtually anyone in the ICT industry; this is what has hitherto been referred to as a code of conduct, in this paper. There is however also the IEEE/ACM code (SECEPP) which is aimed specifically at software engineers. This second code was adopted in 2004 by both the ACS (Davidson, 2004), and the Institution of Engineers, Australia. 
The focus of this paper continues to be on the ACS Code, with lessons on the development of the SECEPP code being drawn on, for recommendations for changes to it.

In 2003 the ACS established a national Committee on Computer Ethics (CCE). Amongst its terms of reference is 'to develop and propose relevant codes of conduct' (ACS CCE, 2003, p 5). The ACS Code is in need of change (Bowern, 2003; Burmeister, 2000) because it is dated, and does not reflect ethical issues arising from the technological developments which have occurred since the last major revision in 1985. Consequently it does not reflect the ethical issues of the widespread adoption of the internet, ubiquitous problems like $\mathrm{Y} 2 \mathrm{~K}$, the human-computer interaction issues created by nanotechnology, nor, for example, does it adequately address the issues of increased use of outsourcing and off-shoring.

The SECEPP code development has yielded lessons to be heeded. The extensive consultation process engaged in by that taskforce needs to be emulated and followed by the ACS. IFIP also advocates an extensive consultation process, arguing that the 'process used to develop a code is as important as the code itself' (Berleur, 2004, p13).

In summary, future versions of the ACS Code of Ethics should:

- $\quad$ incorporate the Code of Professional Conduct, to ensure consistency with the Standards of Conduct, to produce a code consistent with the IFIP code of conduct;

- update and maintain the Code of Professional Practice as an equivalent to the IFIP code of practice; and

- $\quad$ rationalise the way that a part of the code is incorporated in the National Regulations to mandate its use, and the way that other parts of the code can be more easily updated.

\section{DEFICIENCIES IN THE ACS CODE}

A recent ACS report, including a small survey of ACS members active in the computer ethics field, has identified some deficiencies and potential improvements, as follows, in the ACS Code (Bowern, 2003).

- The meaning and use of the Code needs to be clarified, to explain exactly what role the Code does, and should play, as a way to provide guidance and education.

- The role and activities of the Disciplinary Committee in the ACS should be reviewed and amended, if required.

- Consideration is required as to whether the Code should take into account the fact that ACS members come from different cultural backgrounds, and that they may interpret some of the clauses in different ways.

- The code should be consistent with international standards since, although the software is developed or designed in Australia, it has international consequences.

- An editing process to resolve these existing issues should be established, ensuring that the Code is maintained to reflect the changing nature of the ICT industry.

The ACS CCE have identified the following additional deficiencies:

- In 1985 the "C" of ICT was not part of the self-description of the ACS membership. The code only indirectly addresses " $\mathrm{C}$ " type issues at this time.

- Unlike some other codes around the world, the ACS code has no system of prioritisation, for the inevitable situations of conflict between clauses in the code.

- The power of sanction (disciplinary committee) relationship to the code is poorly defined.

- There is a need to resolve issues to do with a multiplicity of codes of ethics. 
Consider this last point. As mentioned already, in addition to the ACS Code of Ethics, the ACS has adopted the SECEPP code. Then too, there are many people in the ICT industry who belong to specialist groups (management consulting, graphic design, software engineering, systems administration, human-computer interaction, and more). In some of these there are codes of ethics specific to that group. For example, the Systems Administrators Guild of Australia formed their own working group on Ethics, because they saw the ACS code as too general, lacking specificity for their work. So they came up with their own code of ethics (Lance, 1994). Work needs to be done to define the relation of the ACS code to these other codes, and to consider the following issues. Should there be one single code for all ICT professionals? What about in situations like SECEPP, a second code adopted by the ACS, what happens if there is conflict between such a code and the ACS code?

\section{Disciplinary Committee}

The roles and responsibilities of the ACS Disciplinary Committee are described in the Society's Rules and Regulations. IFIP argues that 'no code has any value in terms of public duty unless it is associated with a power of sanction such as disciplinary procedures' (Berleur, 2004, p12). However, Anderson, et al (1993) have argued that codes as education serve a useful function in educating and guiding decision making.

Whilst a laudable aim, the authors contend the IFIP view is not currently achievable. Professionalism in ICT, certainly in Australia, is still not at the same level as in engineering, medicine and law. As shown above, in Australia it is possible for a member of the professional society, who has been called to account for a disciplinary matter, to simply resign their membership. Upon their resignation, no further action by the professional society can be taken. However, in other professions, such as medicine, such opting out of the society is not possible. For this reason, it is the view of the authors that the greater emphasis ought to be on incentive and education, rather than on discipline, in regards to a code of ethics in ICT.

\section{Cultural aspects}

Australia has a significant multi-cultural population, which is also reflected in its ICT workforce. Certainly the Code's audience consultation process should include members who come from different cultural backgrounds.

One debate is whether the code should contain clauses reflecting the cultural differences of its members. Part of this debate is whether the clauses of the Code should have a common interpretation, or allow for contextual and cultural variances. IFIP has argued (Berleur, 2004), on the basis of Kant's 'categorical imperative', for a universalisation, in which a code contains necessary 'minimum criteria, conditions, and requirements' applicable to all members of a professional society, regardless of cultural, social and/or legal context. This is very different from the SECEPP approach (cited above) which argues against a Code of Practice as a statement of minimal standards and argues for a Code including aspirational elements directing a striving for quality.

The authors argue that it is not an issue of cultural debate whether testing reduces the risks of software failure, for example. The ethical responsibilities of a practising professional, embodied in a code of ethics, are dictated by that profession and its technology. The profession knows the best standard (its code of practice) to satisfy these responsibilities. 


\section{National aspects}

Gotterbarn (1997) describes the membership of the task force for Software Engineering Ethics and Professional Practices. It comprised people predominantly from North America and Europe, with a few other members, including one from Australia. During the development of the draft codes Gotterbarn found that North American contributions to the codes predominantly followed obligations/rights ethics, whereas the bias in Europe was towards virtue ethics. His study identified that Middle Eastern and Australian views did not easily fall into either of these categories.

To the authors of this paper, the important point is to recognise that there are different approaches to ethics and to ensure that they are considered in the development of codes for ICT ethics. These different approaches - do something because it is the right thing, or do something because it is the will of some deity, or do something because it will produce the greatest good - address the basis for a particular belief. The affirmation of intellectual property, for example, can be based on any of these approaches to ethics; but once IP is affirmed in a code it is not subject to cultural relativism. The ACM/IEEE SECEPP sought principles, consistent with each type of ethics, that were standards of software engineering.

\section{International aspects}

The ACM and IEEE are international organisations and the task force was established to recognise that international character. An objective of the task force was to establish a code which would be accepted internationally. The ACS does have international members, and has entered into reciprocal agreements with a number of overseas computer societies, including several in South East Asia. However, the ACS does not have the same sort of international ambitions as those of the ACM and IEEE. Therefore it might be argued that any redevelopment of the ACS code would generally focus on the needs and issues relating to Australian ICT professionals, although those of the international members should not be forgotten.

However, the development of computer systems and software are international activities, and have international impact; and those aspects must be reflected in codes of ethics. If the ACS is to meet the needs of the profession, it is the needs of the international ICT profession that must be met. If the ACS comes up with a principle that is uniquely Australian, then we should question whether it really was a principle of the profession.

\section{Guidance and education}

Further work is needed to identify how the ACS Code can best provide guidance and education to its members. Current attempts by the $\mathrm{CCE}$ at accomplishing this are mainly through better communication and publicity of the code to ACS members.

Some members of the CCE have produced a set of case studies related to each of the clauses in the ACS Code (ACS Cases, 2004), which have been publicised to members. Since late 2004 the CCE has arranged for a regular column in Information Age, the ACS bi-monthly magazine for members and other professionals in the industry. The column seeks to promote the code, and discuss the ethical aspects of current ICT news items or scandals. The case studies are one source of material for these articles. 
The CCE will also seek to arrange regular sessions at the ACS Annual Conferences at which industry and academic speakers can address issues of the code of ethics. Already greater use of the ACS web site has been made for this purpose.

Advice should be provided on how the Code would apply to the wide range of ACS members, some of whom are not directly involved in systems development, for example ICT professionals dealing directly with customers, such as some empirical software engineers. If the ACS Code is to cater to the widest possible interpretation of 'ICT professional', it must be examined for its applicability to all aspects of the profession. An excellent example has been set through the ACM/IEEE Software Engineering Code, that has recently been adopted by the ACS for its members who are software engineers (Davidson, 2004). The adoption of the software engineering code is another contribution to the specificity of codes for the ACS.

\section{A POSSIBLE APPROACH TO CODE REVISION}

Moor (1999, p65) defines policies as 'rules of conduct ranging from formal laws to informal, implicit guidelines for action'. So a code of ethics could be considered as a set of policy statements about how a professional should behave, in ICT in this case. The on-going development of technology coupled with the malleability of computers means that there will always be a need to develop new policies.

One framework that will aid ACS deliberations is James Moor's Just Consequentialism. Moor (1999, p65) comments on the problems rising from conflicting ethical theories and believes that 'ethics needs more unifying theories that call upon the various strengths of the traditional approaches to ethics'. His Just Consequentialism theory, or framework, is discussed and summarised with respect to cybertechnology, in Tavani (2004, pp59-60). The framework consists of two steps:

- deliberate over various policies from an impartial point of view to determine whether they meet the criteria for being ethical policies (for example, they do not cause unnecessary harms, and support individual rights);

- $\quad$ select the best policy from the set of just policies arrived at in the deliberation stage by ranking ethical policies in terms of benefits and (justifiable) harms.

This approach would appear to be one way to consider the issues described above, and the CCE will consider its use when revising the ACS Code of Ethics.

\section{THE WAY FORWARD FOR THE ACS}

The next steps in this process of the review of the ACS Code of Ethics, including the Standards of Conduct and the Code of Professional Conduct and Professional Practice, involve wide consultation with ACS members. The CCE has already received input from various individual members, as well as from member representatives. One example of the latter is that of the Director ACS-W (representing the views of women members of the ACS), raising aspects of professional practice in relation to discrimination.

In 2006 the CCE is engaging in more deliberate involvement of the wider membership of the ACS. Input into the process has also been received from the wider non-ACS ICT community. The latter has been achieved through the close ties between the CCE and the Australian Institute of Computer Ethics (AiCE), for example, the topic of the ACS Code review process was the subject of a monthly 
meeting of the Melbourne Chapter of AiCE, in November 2005, with the Director of AiCE, Karen Mather, attending the session from interstate (NSW).

The CCE is basing the next review on the method used in the 1985 review of the Code, which used extensive consultation with ACS Fellows. The ACS has various membership grades, the highest being that of Fellow. In 2006 the CCE will conduct focus group sessions with each of the eight Branches of the ACS. There is one branch for every state and territory in Australia. Each focus group will consist of up to 12 participants comprising Fellows and other members nominated by the Branch Executive Committee. Six of the groups will consider one of the Values and Ideals described in the current ideals of the Code, and the other two will focus on more general topics. Other interested people, particularly Directors and members of Boards, will also be consulted. These focus group sessions will be completed by mid 2006.

In July 2006 Professor Rogerson, the Director of the Centre for Computing and Social Responsibility (CCSR) at De Montfort University UK, will be visiting Australia. Simon Rogerson was the first person to be appointed as a professor of computer ethics in Europe, and he made a substantial contribution to the review of the British Computer Society's Code of Ethics. The CCE seeks to draw on this experience as they bring together the findings of the focus groups, and develop the revised Code. Professor Rogerson will facilitate a meeting of the CCE to help synthesize the results of the focus groups and other submissions, including the proposal by the ACS-W.

In addition to this, ACS will be kept informed about the process through the ACS bi-monthly publication, Information Age. It is envisaged that the redrafted code will be put forward to the November 2006 meeting of the ACS Council.

Lastly, this review process is deemed to be significant to the wider ICT community as well. Just as the review process draws on similar work from overseas, in the USA and in the UK, so it is expected that the process will help inform other societies working through similar issues. The latter will be achieved through disseminating information about the process of the review through Working Groups of the International Federation for Information Processing (IFIP), a process that has already started, given two members of the CCE are IFIP working group members, and more particularly, are part of the IFIP Working Group charged with responsibility for developing Frameworks on Ethics, which has as one of its responsibilities, helping member societies formulate their codes of ethics (IFIP SIG 9.2.2).

\section{CONCLUSION}

Just as a motor vehicle should have regular services, so should a code of professional ethics. With a vehicle there is typically a major service infrequently, and more regular minor services. In the case of the ACS Code of Ethics, there have been numerous minor services and lots of tinkering, since the last major service in 1985. It is long overdue for its next major service.

The use of a suitable code of ethics is necessary for the successful development and implementation of new applications of ICT. It is also necessary for the promotion of public trust in the professionalism of those in ICT. Codes are a tool for assessing the ethics of new technologies, such as nanoizing technology, and new ways of working within ICT, such as the treatment of participants in a testing process, and in outsourcing services to an overseas organisation. Change in ICT is a fact of life. 
Professional societies need to put in place procedural mechanisms to ensure regular (at least every 10 years) reviews of the codes, to ensure their ongoing relevance. The ACS requires ICT professionals to keep up to date with changes in the industry. No less should be required of the professional code of ethics.

How codes of ethics addressing ICT practices are changed requires deliberate thought and planning. One way is to appeal to current best practices rather than naming a specific practice, as technical standards change the particular technical items referred to in the code also change. This is a way to build a code which keeps current with the particular best standards of the profession and overcoming the risk of the code becoming out of date by rapidly changing technology.

In changing a code, there is a need to put metrics in place to ensure the efficacy of those changes. IFIP has developed high level guidelines to assess the strengths and weaknesses of a code of ethics. Such guidelines can help in this process, though more work is needed to turn these metrics into a reliable code assessment tool.

\section{REFERENCES}

ACP (2005) Australian Council of Professions, http://www.professions.com.au/ accessed on 21 February 2006.

ACS CCE (2003) CCE submission to Council, Terms of reference for the national Committee on Computer Ethics (CCE), as defined by the Community Affairs Board of the Australian Computer Society, Sydney: ACS, Nov.

ACS Cases (2004) Case Studies, Australian Computer Society, http://www.acs.org.au/publication/docs/ACS_CaseStudiesFinal.pdf accessed on 21 February 2006.

ACS Codes (2005) Australian Computer Society codes, http://www.acs.org.au/ accessed on 21 February 2006.

Anderson, R. Johnson D, Gotterbarn D, and Perrolle, J (1993) "Using the ACM Code of Ethics in Decision Making", Communications of the ACM, Oct.

Berleur, J., Duquenoy, P., Holvast, J., Jones, M., Kimppa, K., Sizer, R., and Whitehouse, D. (2004) "Criteria and Procedures for Developing Codes of Ethics or of Conduct", International Federation for Information Processing, IFIP-SIG9.2.2, IFIP Framework for Ethics of Computing, Sep.

Bowern, M.E. (2003) Report to the ACS Management Committee on the ACS Code of Ethics Project, Sydney: ACS, Dec.

Bowern, M.E. and Weckert, J. (2005) "Ethics: When a team member embezzles", Information Age, June, viewed 21 February 2006, http://www.infoage.idg.com.au/index.php?id=1381484222

Burmeister, O. K. (2000) "Applying the ACS Code of Ethics", Journal of Research and Practice in Information Technology, 32(2), 107-120.

Burmeister, O.K., and Weckert, J. (2003) "Applying the new Software Engineering Code of Ethics to Usability Engineering: A Study of 4 cases", Journal of Information, Communication \& Ethics in Society, 3(3), 119-132.

Coldwell, R.A. (1987) "Non-professional Practices in Computing: Some Thoughts on the Next Decade or So", The Australian Computer Journal, 19(4), Sydney: ACS, November, 215-218.

Davidson, P. (2004) "ACS and IEAust jointly adopt software ethics, practice code", Information Age, Apr, viewed 22 February 2006, http://www.infoage.idg.com.au/index.php?id=912845172. 
Fairweather, N.B. (2001) No PAPA: "Why Incomplete Codes of Ethics are worse than none at all", in Readings in CyberEthics (eds. R.A. Spinello and H.T. Tavani), Jones and Bartlett Publishers, Sudbury, MA.

Gotterbarn, D. (1996) "Establishing Standards of Professional Practice”, in The Responsible Software Engineer, ed. Colin Meyer, Springer Verlag.

Gotterbarn, D. (1997) "The Professionalization of Software Engineering and its significance for Ethics Education”, IEEE, Frontiers in Education. Proceedings 1997.

Gotterbarn, D. et al. (1999) "Software Engineering Code of Ethics is Approved" in Communications of the ACM 42:10 102-107

Gotterbarn, D. (2000) "Two Computer-Related Codes", Perspectives on the Professions, 19(1).

Ladd, J. (1995) "The Quest for a Code of Professional Ethics: An Intellectual and Moral Confusion", in Computers, Ethics and Social Values (eds. D.G. Johnson and H. Nissenbaum), Prentice Hall, Englewood Cliffs NJ.

Lance, K. (1994) "Crafting a Code of Ethical Conduct”, SAGE-AU Code of Ethics, Systems Administrators Guild of Australia Annual Conference.

Luegenbiehl, H.C. (1983) “Codes of ethics and the moral education of engineers". Business and Professional Ethics Journal, 2(4), 41-61.

Moor, J. (1999) “Just consequentialism and computing”. Ethics and Information Technology 1(1), 65-69.

SECEPP, (1999) IEEE-CS/ACM Software Engineering Code of Ethics and Professional Practice, Version 5.2.

Tavani, H.T. (2004) Ethics and Technology: Ethical Issues in an Age of Information and Communication Technology. John Wiley and Sons, Inc, Hoboken, NJ. 
